\title{
Balkanologie
}

Balkanologie Revue d'études pluridisciplinaires

Vol. IX, n' 1-2 | 2005

Volume IX Numéro 1-2

\section{Georgelin (Hervé), La fin de Smyrne, du cosmopolitisme aux nationalismes}

Paris : CNRS, 2005, 250 pages.

Joseph Krulic

\section{(2) OpenEdition}

\section{Journals}

Édition électronique

URL : http://journals.openedition.org/balkanologie/2026

DOI : 10.4000/balkanologie.2026

ISSN : 1965-0582

\section{Éditeur}

Association française d'études sur les Balkans (Afebalk)

Édition imprimée

Date de publication : 1 décembre 2005

ISSN : 1279-7952

\section{Référence électronique}

Joseph Krulic, " Georgelin (Hervé), La fin de Smyrne, du cosmopolitisme aux nationalismes », Balkanologie

[En ligne], Vol. IX, n 1-2 | 2005, mis en ligne le 14 janvier 2010, consulté le 17 décembre 2020. URL http://journals.openedition.org/balkanologie/2026 ; DOI : https://doi.org/10.4000/balkanologie.2026

Ce document a été généré automatiquement le 17 décembre 2020.

(c) Tous droits réservés 


\section{Georgelin (Hervé), La fin de Smyrne, du cosmopolitisme aux nationalismes}

Paris : CNRS, 2005, 250 pages.

Joseph Krulic

\section{RÉFÉRENCE}

Georgelin (Hervé), La fin de Smyrne, du cosmopolitisme aux nationalismes, Paris : CNRS, 2005, 250 pages.

Ce livre, issu d'une thèse, constitue, au carrefour de l'histoire sociale, de l'analyse des nationalismes et de l'histoire des relations inter-nationales, une contribution majeure à l'analyse de la dernière période, c'est à dire après 1878 , de l'empire ottoman. La plupart des lecteurs penseront, au regard de l'histoire «yougoslave» des années 1990 et du souvenir de l'exode des Grecs en 1923, à la problématique très « bosniaque » des temps, heureux ou supposés l'être, de la coexistence, cosmopolite ou interethnique, impériale précédent l'« épuration ethnique » nationaliste. Mais ce n'est pas la seule, ni même la principale, problématique, en dépit du titre, qui parcourt l'ouvrage. D'une part, parce que l'auteur ne verse jamais dans la simplification, bien au contraire. D'autre part, parce que les habitués des thèses d'histoire sociale, notamment sur la France de l'ancien régime, y reconnaîtront un livre d'histoire sociale. Son plan est classiquement thématique, avec une première partie qui analyse, à la manière de Fernand Braudel, la géohistoire de très longue durée de la région (un territoire non national; une région féconde et hospitalière depuis l'antiquité, Smyrne: une urbanité hors du cadre national, sub-urbanisation : logique économique et sociale); une deuxième partie plus sociologique («L'école à Smyrne: cultiver l'entre-soi») se place dans le sillage de certains sociologues français de la haute bourgeoisie et de l'éducation (nous pensons notamment, au couple de sociologues Poinçon-Chariot); une troisième partie («Réjouissance, vie privée et loisirs : rencontrer les autres») qui étudie la sociabilité, concept et/ou réalité très en vogue depuis le milieu des années 1970, notamment parmi 
les spécialistes de la France d'avant 1789 ; une quatrième partie ( Les millets dans la vie politique: vivre ensemble»), plus attendue des "balkanologues»; et une cinquième partie, qui justifie le titre ("Épilogue meurtrier: un cosmopolitisme à détruire »), où l'événement, la politique, la guerre, voire l'histoire-bataille, le temps court qui succède à la très longue durée géo-historique et à la longue durée socioéconomique ou socioculturelle reprend ses droits. Entre les deux, l'auteur dissipe quelques fausses continuités : ainsi le grec parlé à Smyrne ne rattache pas au grec parlé en Asie mineure dans l'antiquité - dont on trouve un exemple dans le "grec pontique " (c'est-à-dire du Pont-Euxin ou de l'est de la Turquie) - mais au grec parlé dans les îles grecques, ce qui signifie que, probablement que la population grecque de Smyrne résulte largement d'une émigration, depuis le XVI ${ }^{\text {ème }}$ siècle, de Grecs des îles en Asie mineure.

2 L'auteur veut explorer cette société de pied en cap, avec son soubassement matériel (géographie, économie), ses étages sociaux et culturels et son toit politique et religieux. Loin, cependant, de lui, une quelconque rigidité économiste, un monisme culturaliste ou un so-ciologisme trop schématique. Il s'efforce d'illustrer ou de cristalliser son analyse sur des moments de la société - que la tradition issue de Marcel Mauss qualifierait de «fait social total »- comme la célébration des «Pâques orthodoxes » (pp. 104-106), marquées par des manifestations hostiles aux juifs du passé mais aussi aux juifs locaux, ou le ramadan (pp. 106-107) où l'auteur remarque, suivant une anthropologie que la "nouvelle histoire» a contribué à répandre, "qu'on peut rapprocher certains éléments du ramadan des célébrations du carnaval : l'inversion de l'ordre courant, du jour et de la nuit ».

3 Avant 1918, les non musulmans et les non turcs sont majoritaires (environ deux tiers de chrétiens et quelques milliers de juifs vers 1881) dans Smyrne, surnommé «la ville infidèle ». Le grec y apparaît comme la langue majeure mais les réseaux privés d'écoles enseignent les nombreuses langues étrangères qui ont chacune leur utilité ou leur prestige. Le français est la langue la plus huppée au point, qu'après 1918, l'éducation des jeunes filles aisées d'Asie mineure a été raillée en Grèce comme celle du «français et piano ». En soi, cette situation de cosmopolitisme est banale dans un empire et notamment dans l'empire Ottoman. Toutefois, après 1878 , comme on le sait, l'empire Ottoman subit une double poussée, ou le double volet géographique d'une même poussée des nationalismes des pays orthodoxes: d'une part, l'affirmation des Étatsnations des Balkans, soutenus par la Russie et, d'autre part, une poussée de la Russie dans le Caucase et en Asie centrale. Smyrne accueille de nombreux réfugies turcs fuyant les Balkans. Vers 1912, la ville apparaît alors comme un îlot cosmopolite dans une Asie mineure qui a entamé, malgré la persistance de minorités arméniennes ou grecques, un processus de "turcisation » avec la généralisation de l'État-nation comme forme politique dans la région et, en tout état de cause, avec la révolution des Jeunes Turcs de 1905. C'est dans le cadre de ces évolutions que l'auteur peut intituler son dernier chapitre « un cosmopolitisme à détruire ». L'épisode final pose de nombreux problèmes d'interprétation historique. L'incendie de la ville est généralement attribué aux troupes de Mustapha Kemal, sur le fondement de nombreux témoignages (p. 203). Mais, ce qui incontestable, c'est la volonté de détruire les élites autochtones (p. 215). Le patriarche grec est assassiné par la foule turque, avec la complicité apparente du général turc responsable sur place, Nurretin Paşa (p. 217). Les autres aspects de cette conquête font songer à la problématique de l'épuration ethnique (" humilier et violer », 
p. 218, "assassiner et déporter les hommes, ", p. 219) ou, si l'on reste dans le contexte de la Première Guerre mondiale, aux formes de violence les plus dégradantes. L'auteur se réfère à l'ouvrage de Stéphane Audoin-Rouzeau, L'enfant de l'ennemi, 1914-1918, (Aubier, 1995), qui analyse les viols des Allemands dans le nord de la France. Il note que les Occidentaux sont restés passifs devant les conquêtes kémalistes ce qui, là encore, nous évoque d'autres refus d'intervenir. Comme beaucoup de chercheurs et d'intellectuels, Hervé Georgelin éprouve la nostalgie de ce cosmopolitisme des cités orientales de la Méditerranée orientale qui ont disparu (p. 230) après la Première Guerre mondiale (Odessa, Smyrne), pendant la Seconde Guerre mondiale à cause du nazisme (Thessalonique), dans les années 1950 à l'époque du Passéisme et du régime militaire turc (Alexandrie et Istanbul), mais il note que ce processus est corrélée à une « cosmopolitisation » des métropoles occidentales dans le cadre de la globalisation. Le cosmopolitisme des âges impériaux a légué des significations ou des problèmes à l'âge de la mondialisation.

4 Toutefois, cette analyse nous paraît d'un optimisme excessif. Certes, en tant qu'analyste ou intellectuel, on peut partager la fascination ou le regret pour une société qui avait réussi, à l'instar de l'Autriche-Hongrie d'avant 1914, de manière imparfaite, à faire coexister plusieurs groupes linguistiques ou religieux. Mais l'auteur constate que ce « cosmopolitisme » a sombré dans la violence nationaliste et nous pourrions ajouter qu'il ne fut pas le seul. L'auteur n'aborde pas de front le problème : le cosmopolitisme impérial est-il condamné à finir dans le nationalisme violent ? De nombreux auteurs, d'Ernst Gellner à Alain Dieckoff, nous ont appris qu'il fallait prendre intellectuellement - le nationalisme au sérieux. Le nationalisme n'est pas, comme nous voudrions le croire, un accident intermittent qui survient pour perturber un "cosmopolitisme" foncièrement bon, un peu comme l'homme selon Jean-Jacques Rousseau serait naturellement bon et corrompu par la société. Le nationalisme est un phénomène récurrent, qui a, notamment, détruit toutes les sociétés cosmopolites ou multiethniques qui ont tant fasciné les intellectuels depuis les années 1980 (Vienne 1900, Istanbul d'avant 1918 ou 1964, Beyrouth avant 1975, Sarajevo avant 1992 etc.). L'objet du livre est, dans une large mesure, une monographie. Mais le point de départ était bien une interrogation plus générale sur la fin des cités cosmopolites de l'espace méditerranéen. Le livre constitue, toutefois, une solide contribution à cette problématique. 